D.O.I: $10.3895 /$ gi.v1i1.1802

\title{
ESTUDO COMPARATIVO ENTRE OS MÉTODOS FMEA E HAZOP APLICADOS À PRODUÇÃO DE BIOETANOL
}

\section{COMPARATIVE STUDY BETWEEN HAZOP AND FMEA METHODS APPLIED TO THE PRODUCTION OF BIOETHANOL}

\author{
Marcelo Giroto Rebelato ${ }^{1}$; Leonardo Lucas Madaleno ${ }^{2}$; Gustavo Borba Ferrari ${ }^{3}$; Andréia Marize \\ Rodrigues ${ }^{4}$; \\ ${ }^{1}$ Universidade Estadual Paulista Júlio de Mesquita Filho - UNESP - Jaboticabal - SP - Brasil \\ mgiroto@fcav.unesp.br \\ ${ }^{2}$ Centro Estadual de Educação Tecnológica Paula Souza - FATEC - Jaboticabal - SP - Brasil \\ leoagro@gmail.com \\ ${ }^{3}$ Universidade Estadual Paulista Júlio de Mesquita Filho - UNESP - Jaboticabal - SP - Brasil \\ borbagustavo@hotmail.com \\ ${ }^{4}$ Universidade Estadual Paulista Júlio de Mesquita Filho - UNESP - Jaboticabal - SP - Brasil \\ andreiamarize@fcav.unesp.br
}

\begin{abstract}
Resumo
O objetivo deste trabalho consiste em apresentar um estudo comparativo entre os métodos FMEA $e$ HAZOP aplicados ao ambiente de fabricação do bioetanol. O trabalho desenvolve, na forma de indicadores categóricos congruentes com a lógica fundamental dos chamados "métodos de análise de causas raizes de problemas", oito critérios com vistas ao confronto entre FMEA versus HAZOP. Em seguida, ponderam-se quantitativamente os critérios desenvolvidos. Por fim, comparam-se os dois métodos sob o panorama de cada um dos oito indicadores desenvolvidos. $O$ trabalho de ponderação dos critérios e posterior confrontação entre FMEA x HAZOP foi realizado por meio do método Analytic Hierarchy Process (AHP). Os julgamentos necessários ao método AHP foram realizados por uma equipe de especialistas oriundos da indústria sucroenergética paulista. O teste de consistência mostrou que os valores atribuídos às prioridades relativas podem ser julgados consistentes. Como resultado, o método HAZOP foi considerado cerca de duas vezes e meia superior ao método FMEA dentro do contexto estudado.
\end{abstract}

Palavras-chave: método FMEA; método HAZOP; método AHP; produção de bioetanol.

\section{Introdução}

O processo de produção do bioetanol carrega um alto risco inerente, pois envolve a fabricação de um produto facilmente inflamável. Enquanto as ignições são um sério risco a qualquer indústria, em uma planta produtora de biocombustíveis estas podem causar incêndios e explosões com prejuízo de algumas centenas de milhares de dólares ao produtor, além de mortes e/ou lesões permanentes aos operários. Ademais, o processo produtivo do etanol é do tipo contínuo puro. Isto significa que, em caso de interrupção de qualquer uma das etapas produtivas, por falha 
humana ou defeito em equipamentos, toda a linha produtiva pode ser paralisada por um período de tempo indefinido. Panes operacionais, portanto, podem resultar em perdas humanas e significativos prejuízos econômicos (SMALL, 2008).

Embora a principal preocupação, em uma planta de bioetanol, seja com relação ao processo de destilação, onde altas concentrações de álcool são produzidas, a área de armazenamento de combustível é também considerada de alto risco, pois faíscas elétricas, relâmpagos, impactos de veículos e outros eventos externos podem iniciar a queima do combustível. Além disso, o etanol é uma commodity internacional amplamente negociada entre importadores e exportadores, o que lhe impõe especificações técnicas regulamentadas mundialmente, pois é por meio destas que se garante a qualidade mínima necessária ao seu correto desempenho. Falhas operacionais no chão de fábrica podem comprometer as propriedades do produto final e resultar, ao fabricante, em imputações de responsabilidade direta por danos causados aos consumidores (SMALL, 2008).

Os distúrbios ou falhas presentes em um sistema de fabricação têm como resultado uma série de incidentes indesejados. A primeira providência para prevenção aos incidentes indesejados são as chamadas "medidas de prevenção de falhas" (BELLINI, 2008). Estas envolvem a análise de falhas do sistema as quais, por sua vez, dependem primeiramente da identificação de perigos ou riscos na instalação produtiva, dado que nenhuma ação pode ser tomada para evitar ou reduzir os efeitos de riscos não identificados. Seguidamente, a prevenção da falha tem como meta a consideração de possíveis cenários que levem a consequências indesejáveis (GOULD, 2000).

Neste contexto, FMEA (Failure Mode and Effects Analysis) e HAZOP (Hazard and Operability Studies), são dois métodos de análise e prevenção de falhas muito populares na esfera industrial e no âmbito acadêmico. Ambos são aplicáveis ao ambiente de fabricação do bioetanol, e ambos têm como resultado o planejamento de ações a fim de mitigar ou eliminar riscos eminentes ao processo. Porém, cada método possui seu nível de particular de detalhamento, estruturação e sistemática.

Partindo da hipótese de que o próprio esforço de prevenção de falhas também tem potencial para descuidos, ineficácias, erros ou omissões e que estes desvios são em grande medida dependentes da abordagem metodológica de prevenção que está sendo utilizada, a questão de pesquisa que se delineia é: qual dos dois métodos, FMEA ou HAZOP, é mais eficiente na identificação, análise e mitigação/eliminação de falhas no processo produtivo do bioetanol na indústria sucroenergética?

Desta forma, o objetivo deste artigo é realizar um estudo comparativo entre o HAZOP e o FMEA aplicados ao processo de fabricação do bioetanol. Por tratar-se de uma commodity, o produto apresenta uma baixa rentabilidade, o que exige um processo produtivo sem desperdícios, vale dizer, sem falhas. 
O trabalho é relevante na medida em que se debruça sobre a fabricação do bioetanol de cana, produto que se destaca pela sua sustentabilidade ambiental em um setor crítico para a economia mundial, o setor energético, sendo o Brasil o maior produtor de etanol de cana-de-açúcar do mundo e ocupando posição de liderança nesta tecnologia de produção. $O$ artigo contribui também com o conhecimento sobre as falhas operacionais na indústria sucroenergética e com o esforço de seleção de técnicas a serem aplicadas no incremento da confiabilidade em sistemas de fabricação contínuos em geral.

\section{Metodologia}

O trabalho foi conduzido em cinco etapas metodológicas, a saber:

1) Mapeamento das etapas produtivas da produção do bioetanol - nesta etapa realizou-se a identificação e o estudo das operações unitárias de transformação do caldo extraído da cana em bioetanol com reconhecimento dos principais pontos críticos em termos de efeitos indesejados provenientes de falhas;

2) Estudo do HAZOP e do FMEA - nesta etapa estudaram-se ambas as metodologias para o conhecimento em detalhe de suas características particulares, estruturas e mecanismos de funcionamento;

3) Seleção de critérios de comparação - em conformidade com Gano (2003), com vistas à realização de uma comparação fidedigna entre os dois métodos foram desenvolvidos indicadores coerentes com a lógica fundamental dos chamados root cause analysis (RCA) methods ou "métodos de análise de causas raízes de problemas". Oito critérios, na forma de indicadores categóricos, foram criados para comparar FMEA versus HAZOP. Eles são:

a) Eficácia na descoberta das falhas - esse critério permite comparar os dois métodos em termos da eficácia na descoberta do maior número de falhas, desvios, ou vulnerabilidades (riscos potenciais) do processo produtivo do bioetanol;

b) Eficácia na descoberta das causas das falhas - este critério se presta a comparar os dois métodos em função capacidade de identificação exaustiva das causas dos erros ou falhas;

c) Eficácia na descoberta dos efeitos das falhas - por meio deste critério é possível confrontar os dois métodos com relação à capacidade de descoberta dos efeitos ou consequências provocadas pelos desvios no sistema;

d) Eficácia na descoberta da frequência de ocorrência das falhas - este critério permite identificar qual dos dois métodos é capaz de levantar com maior precisão a frequência de incidência das falhas identificadas; 
e) Eficácia na mitigação/eliminação das causas das falhas - este critério compara o resultado final da aplicação dos métodos, ou seja, permite determinar qual método tem capacidade superior de incrementar a robustez e estabilidade do sistema de fabricação do bioetanol de modo que as causas das falhas deixem de existir ou sejam mitigadas;

f) Adaptabilidade ao ambiente de fabricação do bioetanol - o bioetanol é um produto de baixa diferenciação. Os dois principais combustíveis produzidos pelas usinas são o bioetanol hidratado e o anidro. Estes são produzidos em uma linha de produção do tipo "dedicada", a qual utiliza equipamentos muito volumosos, estáticos e inflexíveis como rolos de pressão, esteiras, tanques, colunas de destilação, trocadores de calor, caldeiras, fornos, bombas, compressores, redutores, motores elétricos, turbinas a vapor, etc. Dentro disso, por meio deste critério, deve-se avaliar qual dos dois métodos em estudo adapta-se melhor ao ambiente de fabricação do etanol;

g) Conhecimento gerado - por meio deste critério podem-se comparar os dois métodos em termos da riqueza de conhecimento gerado aos funcionários e à empresa sobre as falhas, suas causas e efeitos que afetam o processo produtivo do bioetanol;

h) Eficiência econômica - através deste critério compara-se o montante de recursos econômicos materiais e imateriais, ou seja, dinheiro, tempo, equipamentos e pessoas que são necessários a cada um dos métodos para chegar-se à eliminação das mesmas falhas no sistema de fabricação do bioetanol.

4) Ponderação quantitativa entre os critérios selecionados - nesta etapa priorizaram-se as importâncias relativas de cada critério desenvolvido na etapa anterior. Conforme Saaty (2010), a priorização envolve o desenvolvimento de julgamentos em resposta às questões de dominância de um elemento sobre outro quando comparados com relação a certa propriedade. Para isso, utilizou-se o método Analytic Hierarchy Process (AHP), uma ferramenta flexível que é preparada para levar em conta os diversos critérios para o processo de decisão (SAATY, 1991). O AHP é um método que permite a manipulação dos fatores intangíveis de julgamento de maneira simples e compreensível, sendo adequada a problemas de definição de prioridades, avaliação de custos $\mathrm{x}$ benefícios, alocação de recursos, benchmarking, analise de decisão sob-riscos, entre outros (SAATY, 2008);

5) Comparação entre os métodos FMEA e HAZOP - com o desdobramento do método AHP, iniciado na etapa anterior, chegou-se naturalmente à comparação entre o FMEA e o HAZOP. As avaliações necessárias ao AHP, tanto na Etapa 4 quanto na Etapa 5, foram realizadas por uma equipe de cinco especialistas (Tabela 1) pertencentes à cinco empresas sucroenergéticas e com conhecimentos práticos sobre os dois métodos em análise. 
Tabela 1 - Formação da equipe de especialistas no trabalho de comparação

\begin{tabular}{|c|c|c|}
\hline Cargo & Formação & $\begin{array}{c}\text { Tempo de experiência na } \\
\text { indústria sucroenergética }\end{array}$ \\
\hline Gerente da Qualidade & Engenharia de Produção & 12 anos \\
\hline Gerente de Produção & Engenharia Agronômica & 15 anos \\
\hline $\begin{array}{c}\text { Supervisor de Processos }- \\
\text { Destilaria }\end{array}$ & Engenharia Mecânica & 6 anos \\
\hline Supervisor de Produção & Engenharia Química & 10 anos \\
\hline Supervisor de Produção & $\begin{array}{c}\text { Tecnólogo em produção } \\
\text { sucroalcooleira }\end{array}$ & \\
\hline
\end{tabular}

Fonte: elaboração própria

Estes especialistas foram selecionados por conveniência em cinco usinas produtoras de bioethanol localizadas no Estado de São Paulo. O tratamento matemático necessário ao AHP foi realizado por meio da aplicação do software Make It Rational (http://makeitrational.com/features). Existem no mercado diversos softwares de apoio à decisão que utilizam o método AHP. Este software se destaca por conter uma interface gráfica bastante amigável e por permitir que a avaliação multi critérios seja realizada por diferentes participantes, calculando automaticamente a Razão de Consistência (RC) da análise hierárquica.

\section{A fabricação do bioetanol e os principais pontos críticos do processo produtivo}

A descrição das etapas produtivas do bioetanol são baseadas em Rebelato et al (2012) e Rebelato et al (2013). A fabricação do bioetanol inicia-se após a colheita da cana-de-açúcar e seu transporte para a unidade industrial. A matéria-prima que chega à usina é enviada ao setor de pesagem e amostragem. Geralmente, $30 \%$ do material que chega é amostrado por sondas oblíquas ou horizontais. A qualidade do material amostrado é aferida por meio de análises em laboratório e junto com a pesagem (mensuração da massa de cana + impurezas) tem-se o total de açúcares que serão transformados em produtos finais.

O projeto de uma planta de bioetanol é desenvolvido para que o máximo do açúcar contido na matéria-prima seja transformando em açúcar e álcool. No entanto, mesmo no melhor processo industrial as perdas de açúcar ocorrem (perdas aceitáveis) e existem ainda as perdas que não são contabilizadas por serem impossíveis de serem mensuradas. Os produtos finais são fabricados e determina-se a eficiência do processo pela quantidade de açúcar que adentrou a fábrica e quantidade de produtos finais obtidos.

Nesse contexto, o processo na unidade fabril se inicia com o preparo da matéria-prima por meio da passagem da cana por conjuntos de facas e desintegradores, cuja função é abrir as células da cana e expor seu conteúdo para que seja submetida a alguma forma de extração de caldo: por moenda ou por difusor. A extração por moenda é realizada por pressão, enquanto a realizada por difusor é feita através da lavagem do material (osmose e lixiviação). Os dois métodos possuem 
extração aproximada de $98 \%$ de sacarose no caldo e a perda aceitável de açúcar no bagaço (primeiro resíduo do processo) é de até $2 \%$ de Pol. A Pol é a medida da quantidade de sacarose aparente no caldo e é realizada por um aparelho denominado polarímetro.

Com o processo de extração obtém-se o caldo primário (produção de açúcar) e secundário (produção de bioetanol), que podem ser submetidos ao tratamento para retirada de algumas impurezas que os acompanham. Esse tratamento é opcional, porém caso seja empregado, utilizamse de métodos físicos por meio da peneiragem (peneira rotativa) para retirada do bagaço misturado ao caldo e, químico através da mudança de $\mathrm{pH}$ e temperatura, que faz com os materiais que são solúveis tornem-se insolúveis e possam ser removidos.

Para o tratamento químico aplica-se ao caldo hidróxido de $\mathrm{Ca}(\mathrm{OH})_{2}$ (processo denominado caleagem) que faz com que o pH aumente de 4,5 a 5,5 para 6 a 6,5. Após isto, o caldo caleado é submetido a um aumento rápido de temperatura $\left(100\right.$ a $\left.105^{\circ} \mathrm{C}\right)$, promovendo a floculação primária (transformação de substâncias solúveis que tornam-se insolúveis). O caldo (caleado e aquecido) passa por um balão de flash (equipamento responsável por eliminar gases incondensáveis que prejudicam o processo de sedimentação de impurezas) e adiciona-se polímero para promover a floculação secundária. Nesta, os flocos primários se agrupam tornando-se mais pesados, o que facilita a separação. Após a aplicação do floculante o caldo entra no equipamento decantador, cuja função é separar o caldo clarificado do lodo (ou borra).

O caldo clarificado segue para a produção de açúcar ou bioetanol e o lodo é encaminhado aos filtros de recuperação de sacarose (filtro rotativo ou filtro prensa). Após a passagem do lodo pelo filtro tem-se, por um lado, o caldo filtrado que volta ao processo de tratamento do caldo e, por outro, a torta de filtro, que é destinada à lavoura para adubação da cana-de-açúcar na área agrícola. Nesta torta, a perda aceitável de sacarose é de até $2 \%$ de Pol. Esse é um dos locais que mais se perde açúcar na produção sucroenergética por erro operacional de regulagem dos filtros.

A próxima etapa é o preparo do mosto. Neste processo pode-se utilizar o caldo, o caldo clarificado, o xarope (obtido por concentração do caldo clarificado) ou o melaço (subproduto da produção de açúcar). Neste preparo busca-se a concentração ideal de açúcares (em torno e 18\% de ART - açúcares redutores totais), de nutrientes $(\mathrm{P} \mathrm{e} \mathrm{N})$, da temperatura (em torno de $32^{\circ} \mathrm{C}$ ) e $\mathrm{pH}$ $(4,5)$, assim como a redução de agentes contaminantes (bactérias e leveduras selvagens) para que o processo de fermentação do mosto, que ocorrerá em seguida, seja otimizado.

Ao mesmo tempo em que o mosto é preparado, ocorre o tratamento do fermento (préfermentação), que nas indústrias brasileiras, é utiliza-se a levedura que já foi usada em fermentações anteriores. O fermento é separado do vinho por método de centrifugação e, em seguida, submetido a um tratamento de diluição com água e aplicação de ácido sulfúrico para abaixar o pH para 2,5 e assim evitar a reintrodução de contaminantes no processo. 
Nas dornas de fermentação o mosto e o fermento são misturados e permanecem por período de aproximadamente seis a oito horas no biorreator. A fermentação é processo bioquímico gerador do bioetanol. As moléculas de sacarose, glicose e frutose, presentes no mosto, são transformadas em bioetanol pelas leveduras. Estas produzem, por um lado, o álcool etílico e, por outro lado, o gás carbônico, entre outros resíduos em menor quantidade.

As usinas brasileiras se dividem na utilização do processo fermentativo em batelada (processo Melle Boinot) ou fermentação contínua. No primeiro tipo, a fermentação é realizada em dornas separadas. Ao final do período fermentativo tem-se o vinho levedurado que é submetido ao processo de centrifugação para separação do levedo do vinho. $\mathrm{O}$ vinho delevurado, que possui concentração alcoólica de 8 a 12\% de etanol, segue para a dorna volante e, em seguida, para o processo de destilação.

No processo contínuo, a fermentação inicia-se numa dorna e segue passando por outras três dornas. Entretanto, cada usina possui um modelo de processo contínuo, no qual varia a quantidade de dornas. Ou seja, a fermentação é realizada em dornas interligadas com tempo suficiente para que ocorra o processo até o final. $\mathrm{O}$ vinho levedurado segue os mesmos passos da fermentação em batelada. Em qualquer um dos métodos a temperatura é controlada em torno de $32^{\circ} \mathrm{C}$, com auxílio de trocadores de calor.

No processo de destilação, o método usado é contínuo (sistemático), sendo dividido em três fases: destilação, retificação (Figura 1) e desidratação. Na destilação, que é feita em colunas A (destilação ou esgotamento), A1 ou A' (epuração do vinho) e D (concentração de produtos mais voláteis), é introduzido o vinho aquecido na coluna A1 e esse desce através de sifões (ligação entre as bandejas das colunas) perdendo o álcool na forma de vapor e chega à base da coluna na forma de vinhaça $(0,02 \%$ de etanol) (Figura 1$)$.

No topo da coluna A retira-se o denominado "flegma de baixo grau" (50\% de etanol) que é encaminhado para a coluna de retificação para ser redestilado. Na coluna $\mathrm{D}$ realiza-se a concentração dos produtos de cabeça e o vapor que sai no topo chega aos condensadores (R e R1) e se transforma em líquido. Parte do condensado retorna para a coluna (denominado refluxo ou retrogradação) e pode ser também levado à coluna de retificação na forma líquida e, parte pode ser separada em forma de álcool "de segunda". Algumas unidades optam por não separar o álcool de segunda (condensado que possui produtos de cabeça e etanol) e a coluna D deixa de ser utilizada. Neste caso, todo condensado é encaminhado para a coluna de retificação.

Na Figura 1, verifica-se a coluna de retificação (processo de retificação) composta por colunas B (concentração) e B1 (esgotamento do flegma). Neste equipamento o flegma é fracionado em etanol hidratado (97\% de etanol, o qual sai próximo ao topo da coluna) e resíduos/subprodutos: a) flegmaça (base da coluna); b) óleo fúsel; c) álcool "de segunda”. O óleo fúsel (denominado 
produto de cauda) é submetido ao processo de decantação para recuperação do etanol que sai no momento em que o óleo é retirado na lateral da coluna. O etanol recuperado retorna para a coluna de retificação.

Figura 1 - Conjuntos de colunas de destilação e retificação e acessórios (condensadores e decantador de óleo fúsel) para produção de etanol hidratado

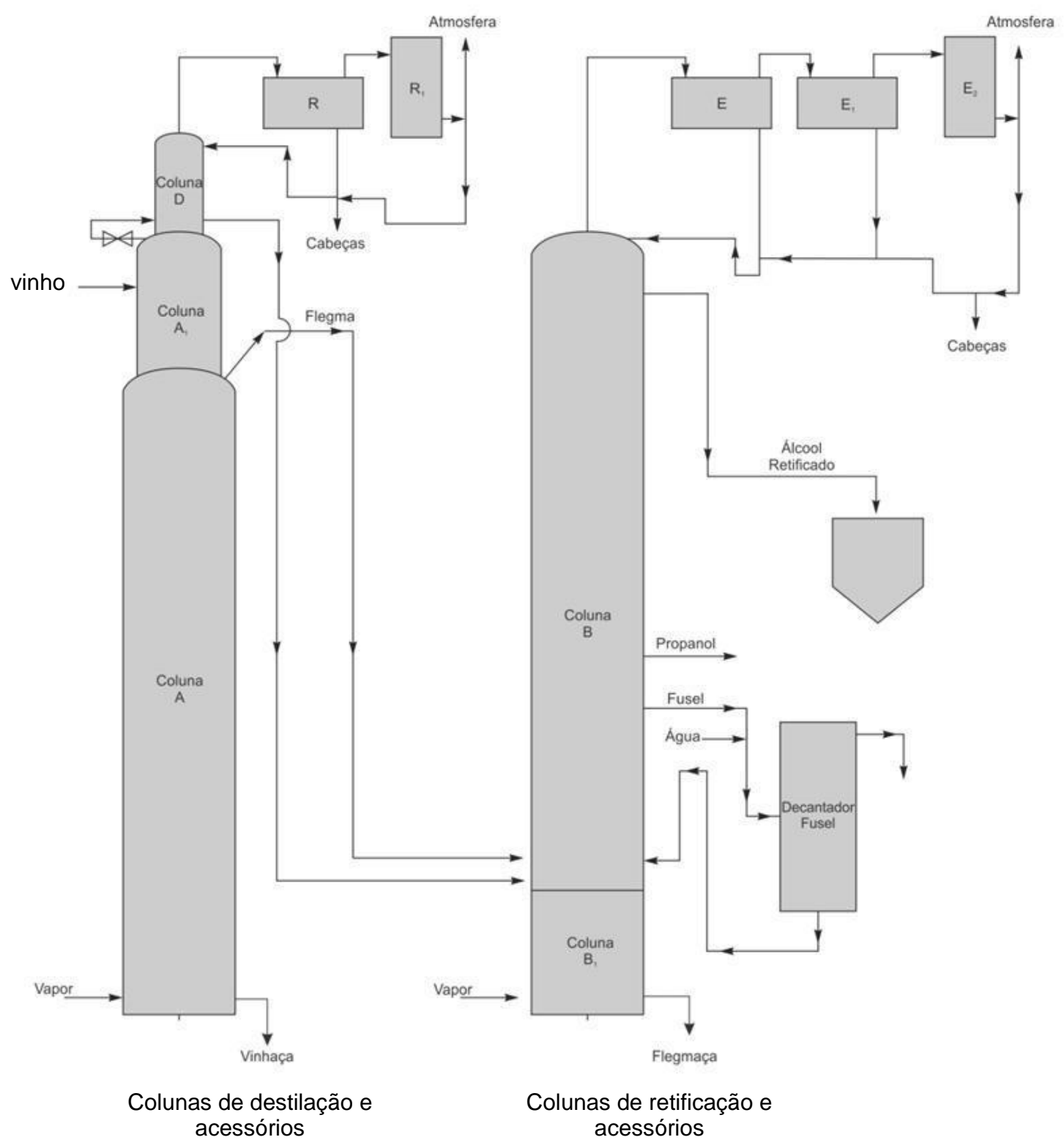

Fonte: Adaptado de Stupiello (2012)

O etanol hidratado pode ser submetido ao processo de desidratação, o qual pode ser realizado por vários métodos, sendo os mais empregados, o extrativo (uso de monoetilenoglicol MEG), o azeotrópico (utilização de ciclohexano) e peneira molécular (zeólita). Por meio de todos estes processos obtém-se etanol anidro 99,9\%. Em seguida, os dois tipos de etanol (hidratado ou 
anidro) podem ser armazenados, o que geralmente é feito em tanques. A principal utilização do etanol hidratado é como combustível em automóveis movidos à gasolina ou etanol (veículos flex), enquanto o etanol anidro é utilizado em mistura à gasolina entre 20 e $25 \%$, conforme estratégia governamental.

Conforme visto, a produção do bioetanol emprega transformações físicas, químicas e biológicas da matéria-prima. Há diversos pontos críticos em termos de oportunidades de falhas e desvios. A Tabela 2 identifica as etapas do processo de produção do bioetanol e as principais falhas que podem ocorrer em cada um delas.

Tabela 2 - Etapas de fabricação do bioetanol e principais pontos críticos

\begin{tabular}{|c|c|}
\hline $\begin{array}{c}\text { Etapa de } \\
\text { fabricação }\end{array}$ & Pontos críticos \\
\hline $\begin{array}{l}\text { Extração do } \\
\text { caldo }\end{array}$ & $\begin{array}{l}\text { 1. Falta de vapor ou eletricidade para o funcionamento das moendas; } \\
\text { 2. Ranhuras dos rolos de extração da moenda inadequadas; } \\
\text { 3. Realização da embebição de modo não adequado em moendas e difusores; } \\
\text { 4. Peneira rotativa (processo físico de tratamento do caldo) entupida; } \\
\text { 5. Contaminação provocada por assepsia não adequada do processo; } \\
\text { 6. Perdas de sacarose e outros açúcares no bagaço pela extração deficiente de moendas ou } \\
\text { difusores; } \\
\text { 7. Se for empregada extração do caldo por difusor: embebição para extração do caldo } \\
\text { inadequada e entupimento da tela que sustenta o "colchão" de cana preparada. }\end{array}$ \\
\hline $\begin{array}{c}\text { Tratamento do } \\
\text { caldo }\end{array}$ & $\begin{array}{l}\begin{array}{l}\text { 1. Erro na dosagem de hidróxido de cálcio } \mathrm{Ca}(\mathrm{OH})_{2} \text { aumentando o } \mathrm{pH} \text { além do nível } \\
\text { recomendado; }\end{array} \\
\begin{array}{r}\text { 2. Perfuração da tubulação de aquecedores de caldo e perda de sacarose no vapor de } \\
\text { aquecimento; }\end{array} \\
\begin{array}{l}\text { 3. Temperaturas de processo não alcançadas que levam a menor degasagem no balão de flash; } \\
\text { 4. Erro de dosagem de polímero; }\end{array} \\
\begin{array}{l}\text { 5. Decantadores mal operados (vazão de entrada de caldo no aparelho com velocidade elevada); } \\
\text { 6eparação defeituosa do lodo do caldo clarificado (caldo clarificado que contém lodo que não } \\
\text { foi separado); }\end{array} \\
\text { 7. Problemas no sistema de filtração do lodo para recuperação da sacarose e outros açucares. }\end{array}$ \\
\hline $\begin{array}{l}\text { Preparo do } \\
\text { mosto }\end{array}$ & $\begin{array}{l}\text { 1. Erro na dosagem da quantidade de açúcares para a fermentação. Os açúcares redutores totais } \\
\text { devem permanecer por volta de } 18 \% \text { para se obter produção de etanol próxima de } 8 \text { a } 12 \% \text { de } \\
\text { teor alcoólico no vinho; } \\
\left.\text { 2. Temperatura do mosto muito elevada (acima de } 35^{\circ} \mathrm{C}\right) \text { que levam a menor eficiência das } \\
\text { leveduras na conversão dos açúcares em bioetanol; } \\
\text { 3. Falta de nutrientes (por erro no processo de tratamento, materiais como melaço que contém } \\
\text { menor teor e a adubação não adequada da lavoura). Os nutrientes servem para a formação de } \\
\text { novas leveduras e manutenção do fermento, que nas usinas são reutilizadas. } \\
\text { 4. Contaminação elevada. Presença de microrganismos (bactérias e leveduras selvagens) que } \\
\text { disputarão o açúcar presente no mosto. }\end{array}$ \\
\hline Preparo do & $\begin{array}{l}\text { 1. Falha no controle da cepa de levedura utilizada, pois pode haver modificação da população de } \\
\text { leveduras (introdução de leveduras selvagens e reprodução sexuada que leva a modificação do } \\
\text { DNA) e diminuir o rendimento de produção de etanol. }\end{array}$ \\
\hline
\end{tabular}




\begin{tabular}{|c|c|}
\hline fermento & $\begin{array}{l}\text { 2. Como o fermento é reutilizável, após o término da fermentação é separado do vinho e } \\
\text { encaminhado para o tratamento. Pode haver erro na diluição do fermento (aumento de chance de } \\
\text { contaminação por bactérias e/ou da toxicidade dos produtos que ficaram junto com o fermento } \\
\text { que causam estresse para a levedura e pode diminuir o rendimento do processo). } \\
\text { 3. Erro na aplicação de } \mathrm{H}_{2} \mathrm{SO}_{4} \text { para abaixar o pH para } 2,5 \text { (buscando eliminação das bactérias). O } \\
\text { pH muito baixo leva a perda de viabilidade do fermento; } \\
\text { 4.Falha no controle no tempo do tratamento do fermento, que pode ser insuficiente para que } \\
\text { reduza a contaminação por bactérias; }\end{array}$ \\
\hline Fermentação & $\begin{array}{l}\text { 1. Falha no controle do tempo de fermentação (deve haver tempo suficiente para que quase todo } \\
\qquad \text { ART seja transformado em etanol); } \\
\text { 2. Velocidade inadequada de alimentação da dorna de fermentação (quanto mais lenta melhor a } \\
\text { adaptação do fermento); } \\
\text { 3. Falha no controle Temperatura da dorna, que deve ser mantida em torno de } 32^{\circ} \mathrm{C} \text {; } \\
\begin{array}{c}\text { 4. Falha na velocidade de centrifugação após o término da fermentação (evitar formação de } \\
\text { produtos indesejáveis como o ácido acético (atraso de centrifugação) e a perda de vinho no } \\
\text { fermento ou de fermento no vinho); }\end{array}\end{array}$ \\
\hline $\begin{array}{c}\text { Centrifugação } \\
\text { do vinho } \\
\text { levedurado }\end{array}$ & $\begin{array}{l}\text { 1.Entupimento dos bicos de separação da centrífuga; } \\
\text { 2. Falha na regulagem da velocidade de centrifugação (permite melhorar a separação dos } \\
\text { contaminantes que saem junto com o vinho); }\end{array}$ \\
\hline Destilação & $\begin{array}{l}\text { 1. Falta de energia na destilaria - o processo de cogeração de energia utiliza caldeira e o bagaço } \\
\text { da cana-de-açúcar como fonte energia, gerando vapor em alta pressão e alta temperatura que } \\
\text { através de uma turbina a gás movimenta um gerador. Esse processo garante a energia para o } \\
\text { funcionamento da destilaria, portanto qualquer problema de caldeira pode prejudicar o } \\
\text { fornecimento de energia no processo. } \\
\text { 2. Regulagem do vapor de aquecimento das colunas. Pouco vapor (aquecimento) leva ao } \\
\text { aumento da perda de etanol na vinhaça e na flegmaça; } \\
\text { 3. Falta de água no processo - este fato pode gerar problemas nos condensadores. Com isso } \\
\text { haveria perda de etanol no vapor, pois com a falta de água no processo os condensadores não } \\
\text { conseguiriam converter o vapor para líquido; } \\
\text { 4. Variações de pressões - falhas no processo produtivo de etanol de mudanças das pressões, por } \\
\text { diminuição ou aumento do vapor adicionado ao processo que podem aumentar as perdas de } \\
\text { etanol nos resíduos; } \\
\text { 5. Possíveis vazamentos na destilaria - pode ocorrer em vários pontos por falhas no processo e } \\
\text { falta de manutenção nos equipamentos. Podem ocorrer problemas operacionais nas colunas de } \\
\text { destilação que resultaria em perdas de etanol no processo; } \\
\text { 6. Temperaturas altas nos condensadores - este problema pode ocasionar perda de etanol por } \\
\text { evaporação e os gases carregados de etanol são lançados ao ambiente; } \\
\text { 7. Bombeamento, tubulações e linhas de envio do etanol de etanol para armazenamento - uma } \\
\text { falha nesta etapa do processo poderia condenar toda a produção de etanol por causa do } \\
\text { vazamento e perda do líquido antes de chegar aos tanques; } \\
\text { 8. Tanques de armazenamento - falhas na manutenção destes equipamentos podem gerar } \\
\text { infecção destes depósitos, além de desperdícios de etanol e último caso resultar em um grande } \\
\text { risco de vazamento e explosão. }\end{array}$ \\
\hline
\end{tabular}

Fonte: elaboração própria

\section{FMEA e HAZOP}

O FMEA é um método voltado à identificação de falhas atuantes e potenciais e seus efeitos em sistemas e processos com o objetivo de definir condutas para reduzir ou eliminar o risco associado a cada falha identificada. $\mathrm{O}$ método avalia a severidade de cada falha relativamente ao 
impacto causado aos usuários, sua probabilidade de ocorrência, e sua possibilidade de detecção. Com base nestas três informações, severidade, ocorrência e detecção, o método FMEA leva à anteposição de quais modos de falha provocam os maiores riscos ao cliente e que, portanto, são dignos de maior atenção (PUENTE et al, 2002).

De acordo com Fernandes e Rebelato (2006) as etapas para a execução de FMEA (Figura 2) são:

a) Identificar modos de falha (eventos que resultam em redução da função e dos objetivos de desempenho do sistema) conhecidos e potenciais;

b) Identificar os efeitos de cada modo de falha e a sua respectiva severidade ou gravidade sob o ponto de vista do usuário;

c) Identificar as causas possíveis para cada modo de falha e a sua probabilidade de ocorrência;

d) Identificar os meios de controle atuais do modo de falha e sua probabilidade de detecção (probabilidade de que a falha seja constatada antes que o produto chegue ao cliente);

e) Avaliar o Nível de Prioridade de Risco (NPR) de cada modo de falha;

f) Avaliar se o patamar do NPR é aceitável ou não;

g) Em caso de NPR em nível inaceitável, definir medidas para a eliminação ou redução do NPR. Isto é conseguido por meio de ações que aumentem a probabilidade de detecção ou reduzam a probabilidade de ocorrência da falha;

h) Definir os responsáveis pela implantação das melhorias, a acompanhar a implantação e recalcular o NPR;

i) Se o novo NPR estiver em nível ainda inaceitável, deve-se replanejar novas medidas de melhorias.

Para determinar-se o risco associado a cada modo de falha multiplica-se a pontuação da severidade (S), pela ocorrência (O) e pela detecção (D). Para classificar os riscos, pode-se ter, por exemplo, uma escala que vai de 1 a 1000 pontos, sendo 1 um baixíssimo risco e 1000 um risco crítico ao usuário. 
Figura 2 - Fluxograma de desenvolvimento do FMEA

Identificar os possiveis modos de falhas e seus efeitos

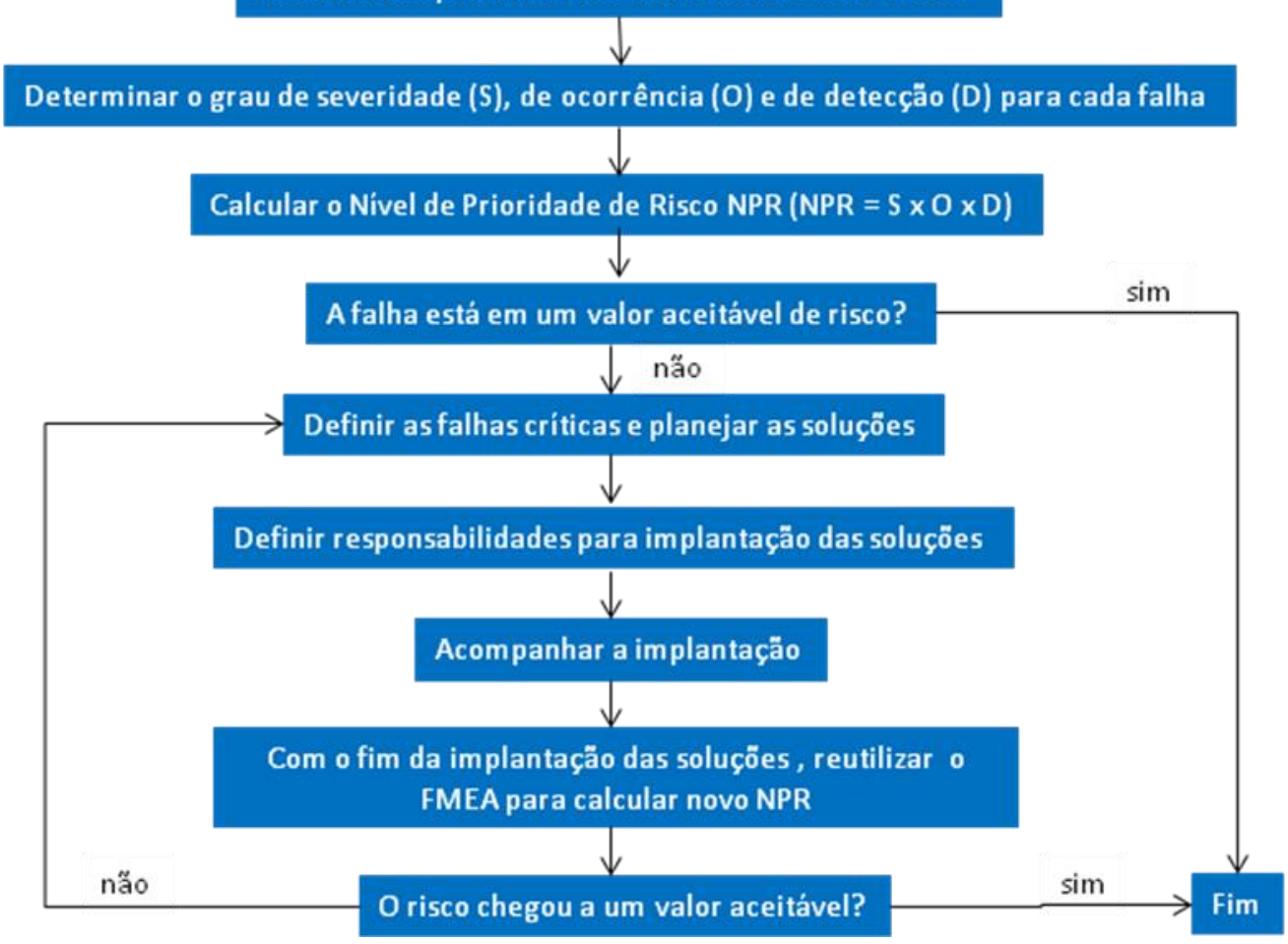

Fonte: elaboração própria

Analogamente ao FMEA, o HAZOP é uma metodologia qualitativa estruturada e sistemática para exame de sistemas (produtos, processos, plantas, atividades) e análise de riscos. Presume que eventos de risco são causados por desvios de projeto ou falhas operacionais. A identificação dos desvios é facilitada pela utilização de desvio de "palavras-guia", que funcionam como uma lista sistemática de perspectivas de desvio (PQRI, 2014). Antes da utilização das palavras-guia devem ser destacados do processo os pontos específicos que são localizados nos fluxogramas do sistema estudado. Estes são denominados "nós" e são individualmente analisados. As palavras-guias são confrontadas com os parâmetros do processo (temperatura, pressão, nível, etc.) gerando os possíveis problemas a serem estudados. A Tabela 3 oferece exemplos possíveis de associações das palavrasguia com os parâmetros (BRITSH STANDARD INSTITUTION, 2001). 
Tabela 3 - Exemplos de parâmetros, palavras-guias e desvios para HAZOP

\begin{tabular}{|c|c|c|}
\hline $\begin{array}{l}\text { Parâmetros } \\
\text { (Variâveis) }\end{array}$ & Palavra-Guia & Desvio \\
\hline Fluxo & \begin{tabular}{|c|} 
Nenhum \\
Menos Mais \\
Reverso \\
Também
\end{tabular} & $\begin{array}{l}\text { Nenhum Fluxo } \\
\text { Menos Fluxo } \\
\text { Mais Fluxo } \\
\text { Fluxo Reverso } \\
\text { Contaminação }\end{array}$ \\
\hline Pressão & $\begin{array}{l}\text { Menos } \\
\text { Mais }\end{array}$ & $\begin{array}{l}\text { Pressão Baixa } \\
\text { Pressão Alta }\end{array}$ \\
\hline Temperatura & $\begin{array}{l}\text { Menos } \\
\text { Mais }\end{array}$ & $\begin{array}{l}\text { Temperatura Baixa } \\
\text { Temperatura Alta }\end{array}$ \\
\hline Nível & $\begin{array}{l}\text { Menos } \\
\text { Mais }\end{array}$ & $\begin{array}{l}\text { Nível Baixo } \\
\text { Nível Alto }\end{array}$ \\
\hline Viscosidade & $\begin{array}{c}\text { Menos } \\
\text { Mais }\end{array}$ & $\begin{array}{c}\text { Viscosidade Baixa } \\
\text { Vicosidade Alta }\end{array}$ \\
\hline Reação & $\begin{array}{l}\text { Nenhum } \\
\text { Menos } \\
\text { Mais } \\
\text { Reverso } \\
\text { Também }\end{array}$ & $\begin{array}{l}\text { Nenhuma Reação } \\
\text { Reação Incompleta } \\
\text { Reação Descontrolada } \\
\text { Reação Reversa } \\
\text { Reação Secundária }\end{array}$ \\
\hline
\end{tabular}

A Figura 3 apresenta um fluxograma do método HAZOP em um processo produtivo. A aplicação inicia-se com a seleção de um nó de estudo (um ponto crítico) do subsistema e identificação um parâmetro presente nesse nó. No próximo passo, gera-se um desvio através da aplicação de uma palavra-guia a um parâmetro do nó. Com a definição do possível desvio, determinam-se as causas e os efeitos. Nessas etapas, a experiência prática dos participantes é de extrema importância. Em seguida, é necessário analisar a existência de meio de detecção do desvio, assim como meios de salvaguardas preventivas e mitigadoras. Definidas as recomendações e ações de melhoria, analisam-se as suas prioridades por meio de critérios como custo, risco, facilidade de execução. Por fim, atribuí-se um responsável para a ação de correção do processo e acompanha-se a efetividade da implantação. 
Figura 3 - Fluxograma de desenvolvimentodo HAZOP

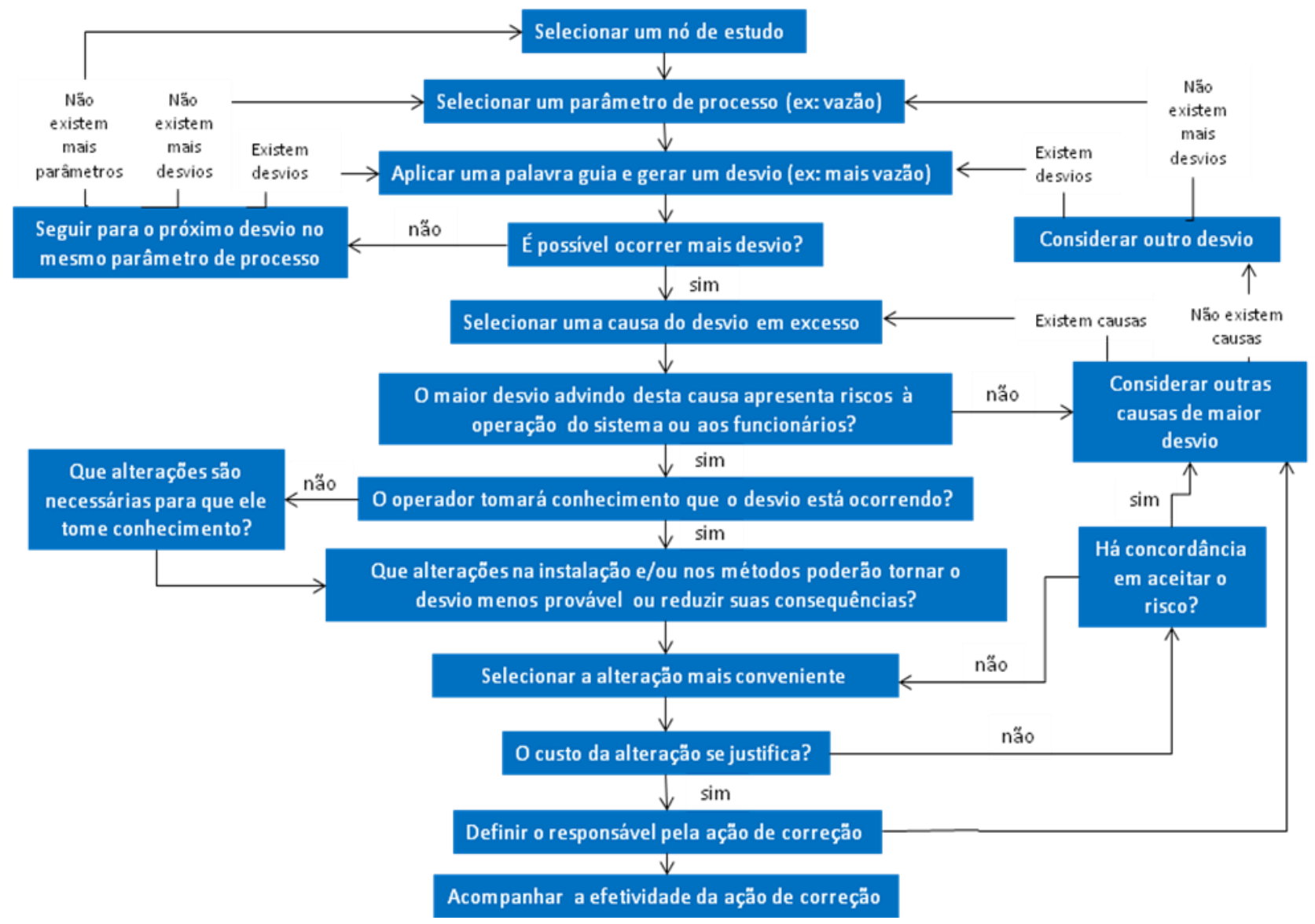

Fonte: elaboração própria

\section{O método AHP}

A estruturação de um problema AHP se inicia com o estabelecimento do objetivo desejado. A partir desse definem-se os critérios numa estrutura em árvore invertida (Figura 4), sendo o objetivo principal a raiz desta árvore. À medida que se afasta da raiz, tem-se os fatores mais específicos (as "folhas”), os quais representam os critérios de avaliação. Para cada grupo de critérios semelhantes que possuem um mesmo "pai”, uma matriz de comparações paritárias (MCP), contendo os níveis de anteposição obtidos por confrontação de um fator com outro, deve ser construída. O princípio do AHP é a geração de um vetor de prioriades pelo cálculo do maior autovetor de cada MCP do problema inteiro (SHIMIZU, 2010). 
Figura 4 - Estrutura de decisão hierárquica no método AHP

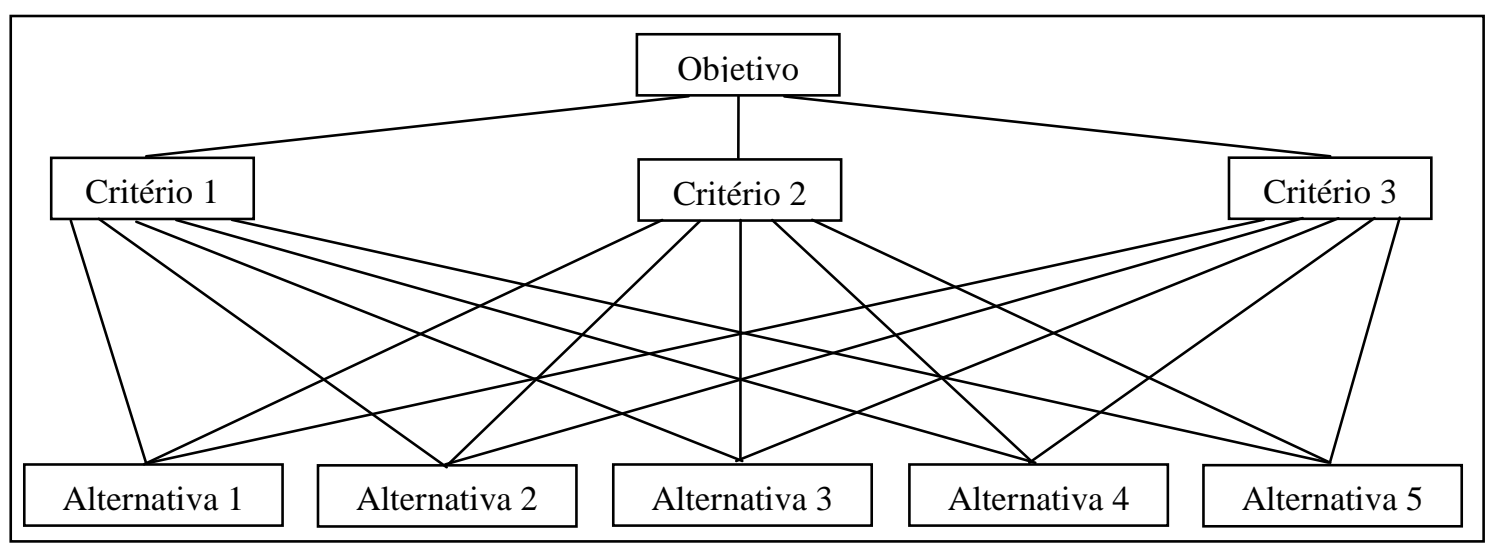

Fonte: elaboração própria.

As comparações paritárias não são feitas em escala absoluta devido à condição dos componentes de uma decisão múlti critérios. Dado que frequentemente o problema é impalpável, isso impede que isoladamente os componentes sejam mensurados usando a mesma escala. $\mathrm{Na}$ comparação paritária, quando o tomador de decisão manifestar sua preferência por um atributo X, como sendo muito mais importante do que o atributo $\mathrm{Y}$, por exemplo, estará atribuindo para o atributo $\mathrm{X}$ peso 5. Caso o tomador de decisão considere que os dois critérios possuem a mesma importância, estará atribuindo o peso 1. A Tabela 4 define e explica o conceito dos pesos utilizados no método AHP (OLIVEIRA et al , 2011).

Tabela 4 - Fatores do AHP para as comparações paritárias

\begin{tabular}{|c|c|c|}
\hline $\begin{array}{c}\text { Intensidade de } \\
\text { importância } \\
\text { (peso) }\end{array}$ & Peso & Explicação \\
\hline 1 & Mesma importância & Os dois atributos contribuem igualmente para o objetivo \\
\hline 3 & $\begin{array}{c}\text { Importância pequena de um } \\
\text { sobre o outro }\end{array}$ & $\begin{array}{c}\text { A experiência e o julgamento favorecem levemente um } \\
\text { atributo em relação ao outro }\end{array}$ \\
\hline 5 & $\begin{array}{c}\text { Importância grande ou } \\
\text { essencial }\end{array}$ & $\begin{array}{c}\text { A experiência e o julgamento favorecem fortemente um } \\
\text { atributo em relação ao outro }\end{array}$ \\
\hline 7 & Importância muito grande & $\begin{array}{c}\text { Um atributo é fortemente favorecido em relação ao } \\
\text { outro; sua dominação de importância é demonstrada na } \\
\text { prática. }\end{array}$ \\
\hline 9 & Importância absoluta & $\begin{array}{c}\text { A evidência favorece um atributo em relação ao outro } \\
\text { com o mais alto grau de certeza }\end{array}$ \\
\hline $2,4,6,8$ & $\begin{array}{c}\text { Valores intermediários entre } \\
\text { os valores adjacentes }\end{array}$ & $\begin{array}{c}\text { Quando se procura uma condição de compromisso entre } \\
\text { duas definições }\end{array}$ \\
\hline
\end{tabular}

Fonte: OLIVEIRA et al $(2011, \mathrm{p} .6)$

Saaty (1991) e Naves (2008) apresentam a modelagem matemática do AHP. Dado que A seja uma MCP genérica, n(n-1)/2 é o número de julgamentos paritários necessários à construção de $\mathrm{A}$, onde $\mathrm{n}$ é o número de elementos da matriz. Nesta, $\mathrm{a}_{\mathrm{ij}}$ indica o julgamento quantificado do par de critérios $\left(\mathrm{C}_{\mathrm{i}}, \mathrm{C}_{\mathrm{j}}\right)$ e $\alpha$ o valor da intensidade de importância. Os elementos de A são: 


$$
A=\left[\begin{array}{cccc}
1 & a_{12} & \cdots & a_{1 n} \\
1 / a_{12} & 1 & \cdots & a_{2 n} \\
\vdots & \vdots & \vdots & \vdots \\
1 / a_{1 n} & 1 / a_{2 n} & \cdots & 1
\end{array}\right]
$$

Se $a_{i j}=\alpha$, então $a_{j i}=1 / \alpha, \alpha \neq 0$.

Se $C_{i}$ é julgado como de igual importância relativa a $C_{j}$, então $a_{i j}=1, a_{i j}=1$ e $a_{i i}=1$, para todo $\mathrm{i}$

Normaliza-se A por meio da expressão:

$$
V i(a j)=\frac{\text { aij }}{\sum_{i=1}^{n} \text { aij }}
$$

Onde: $\mathrm{n}=$ numero de alternativas comparadas;

Vi $\left(\mathrm{a}_{\mathrm{j}}\right)=$ valor normalizado, obtido dividindo os valores das colunas pela soma dos valores das colunas.

Em seguida, calcula-se o vetor de prioridade $\mathrm{W}$ da alternativa $\mathrm{i}$ em relação ao critério $\mathrm{C}_{\mathrm{k}} \mathrm{e}$ determina-se a média de cada linha dos valores normalizados.

$$
\mathrm{W}=\mathrm{Vk}(\mathrm{Ai})=\sum_{\mathrm{j}=1}^{\mathrm{n}} \overline{\mathrm{V} i} \frac{\overline{\mathrm{Aj}}}{\mathrm{n}}
$$

Onde: $\mathrm{W}$ ou Vk $(\mathrm{Ai})=$ Vetor de prioridades.

Então, calcula-se o autovalor $\left(\lambda_{\max }\right)$ por meio da expressão:

$$
\lambda \max =\frac{1}{n} \sum_{\mathrm{i}=1}^{\mathrm{n}} \frac{(\text { Aw }) \mathrm{i}}{\mathrm{wi}}
$$

Onde: $\lambda_{\max }=$ autovalor procurado;

$\mathrm{W}=$ vetor de prioridades;

Aw $=$ vetor resultante entre matriz A multiplicado pelo vetor de prioridades .

Em seguida, calcula-se o Índice de Consistência (IC):

$$
\mathrm{IC}=(\lambda \max -\mathrm{n}) /(\mathrm{n}-1)
$$

Onde: $\lambda_{\max }=$ autovalor procurado;

O próximo passo é o cálculo da Razão de Consistência:

$$
\mathrm{RC}=\frac{\mathrm{IC}}{\mathrm{CA}}
$$

Onde: CA é o índice de consistência aleatória (CA), apresentado na Tabela 5. 
Tabela 5 - Valores de CA em Função da Ordem da Matriz

\begin{tabular}{|c|c|c|c|c|c|c|c|c|c|c|c|c|c|c|c|}
\hline $\mathrm{n}$ & 1 & 2 & 3 & 4 & 5 & 6 & 7 & 8 & 9 & 10 & 11 & 12 & 13 & 14 & 15 \\
\hline $\mathrm{CA}$ & 0,00 & 0,00 & 0,58 & 0,90 & 1,12 & 1,24 & 1,32 & 1,41 & 1,45 & 1,49 & 1,51 & 1,48 & 1,56 & 1,57 & 1,59 \\
\hline
\end{tabular}

Fonte: Saaty (1991, p.27)

Considera-se aceitável uma razão de consistência menor que 0,10.

Por fim, determina-se o nível de preferência das alternativas. Estas devem ser comparadas par a par em cada um dos critérios, de modo análogo ao descrito para a obtenção da importância relativa dos critérios. Efetua-se a valoração global de cada uma das alternativas, de acordo com a expressão:

$$
\mathrm{V}(\mathrm{a})=\sum_{\mathrm{j}=1}^{\mathrm{n}} \text { pjvj(a) }
$$

Onde: V(a) corresponde ao valor global da alternativa analisada;

pj à importância relativa do critério j;

vj ao nível de preferência da alternativa analisada no critério j.

\section{Resultados e discussão}

Em um primeiro momento, cada membro da equipe de especialistas selecionada confrontou, em pares, todos os critérios de comparação desenvolvidos conforme as diretrizes da Tabela 4. Os dados de cada preferência, de cada avaliador, foram introduzidos no software citado. Este calculou a média das avaliações feitas por cada membro da equipe, para cada critério, conforme apresentado na Figura 5.

Figura 5 - Resultado da avaliação para grau de importância relativa de cada critério

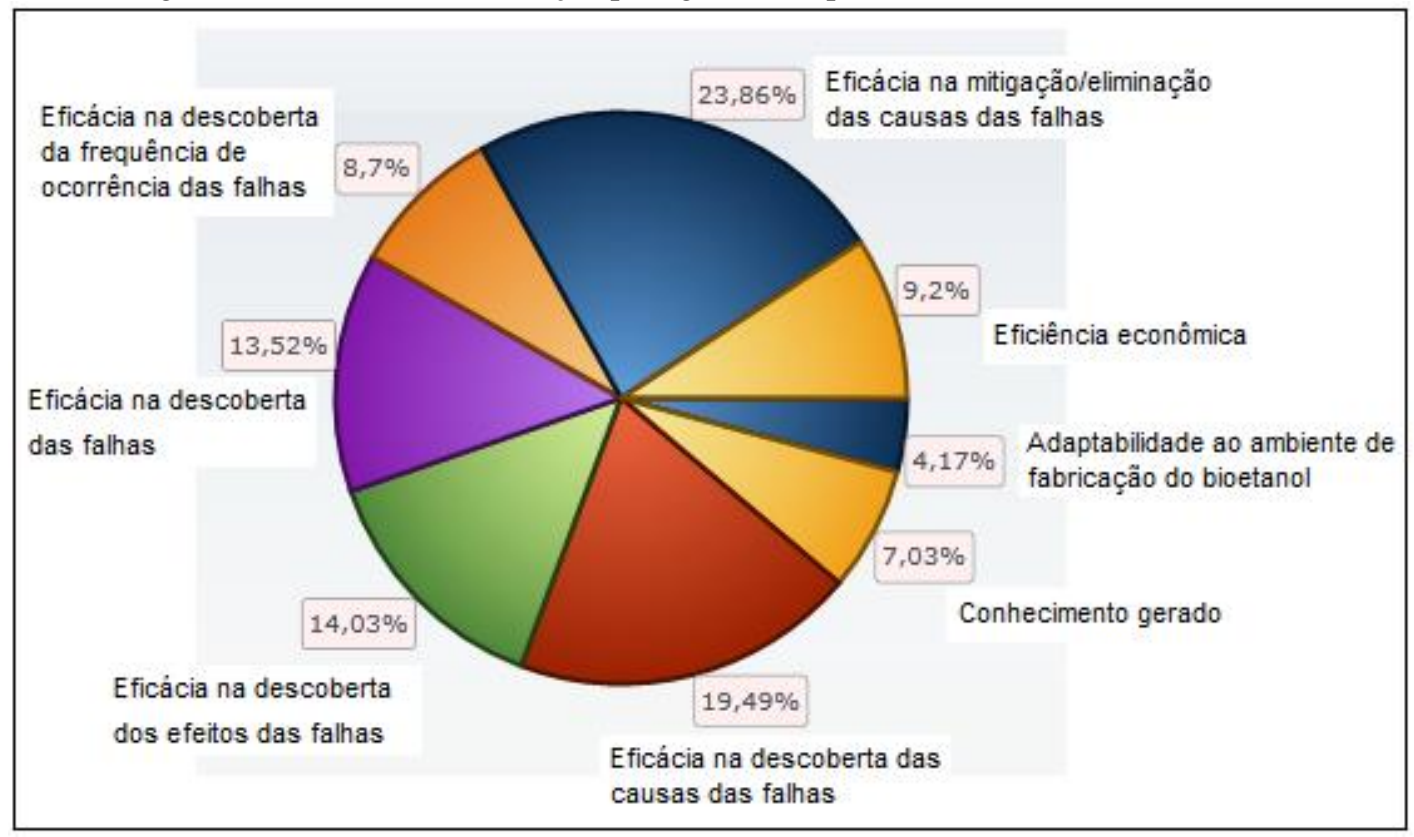

Fonte: Elaboração própria 
Conforme Tabela 6 os resultados da ponderação entre os critérios podem ser divididos em cinco categorias, divididas com base no patamar médio dos critérios. Eliminar eficazmente as causas das falhas $(23,86 \%)$ e descobrir efetivamente quais são estas causas $(19,49 \%)$ são os critérios ligados aos fatores que provocam as falhas, os quais são os mais importantes, sob o ponto de vista dos especialistas (em amarelo). Na segunda categoria (em verde) aparecem os critérios eficácia da descoberta dos efeitos das falhas $(14,03 \%)$ e eficácia na descoberta das falhas $(13,52 \%)$, ambos aos critérios relacionados ao esforço de detecção dos desvios. Na terceira categoria (em roxo), aparecem os critérios eficiência econômica $(9,20 \%)$ e eficácia na descoberta da frequência de ocorrência das falhas os quais, apesar de não tem possuem uma lógica similar, exibem uma pontuação bem próxima. Na quarta categoria (em laranja) tem-se o conhecimento gerado à empresa $(7,03 \%)$ e na última categoria (em azul), e como critério menos importante, a adaptabilidade ao ambiente de fabricação do bioetanol (4,17\%).

Tabela 6 - Critérios de ponderação divididos em cinco categorias

\begin{tabular}{|c|c|}
\hline Critério & Peso relativo (\%) \\
\hline Eficácia na mitigação/eliminação das causas das falhas & 23.86 \\
\hline Eficácia na descoberta das causas das falhas & 19.49 \\
\hline Eficácia na descoberta dos efeitos das falhas & 14.03 \\
\hline Eficácia na descoberta das falhas & 13.52 \\
\hline Eficiência econômica & 9.20 \\
\hline Eficácia na descoberta da frequência de ocorrência das falhas & 8.70 \\
\hline Conhecimento gerado & 7.03 \\
\hline Adaptabilidade ao ambiente de fabricação do bioetanol & 4.17 \\
\hline
\end{tabular}

Fonte: Elaboração própria

Conforme Saaty (1991), uma taxa ou razão de consistência de 0,10 ou menos é considerada aceitável. Foi calculada, neste caso, uma taxa de consistência $\mathrm{RC}=0,026$. Sendo assim, os valores das prioridades relativas estão consistentes.

Em um segundo momento, cada membro da equipe realizou a confrontação entre HAZOP e FMEA sob o ponto de vista de cada critério, levando em consideração o contexto do sistema produtivo do bioetanol.

Os dados foram inseridos no software e, como resultado médio tem-se que em sete dos oito critérios o HAZOP apresentou maior eficácia em relação ao FMEA quando aplicado ao processo produtivo do bioetanol. O FMEA apresentou maior eficácia em relação ao HAZOP somente no critério de eficiência econômica de desenvolvimento. Isto pode ser visualizado pelo gráfico tipo radar apresentado na Figura 6.

Nos demais sete critérios de comparação o HAZOP foi julgado superior ao FMEA sob o ponto de vista da equipe de especialistas. O resultado de ampla superioridade do HAZOP pode ser visto na Figura 7. 
Figura 6 - Resultado da comparação HAZOP x FMEA em gráfico tipo radar

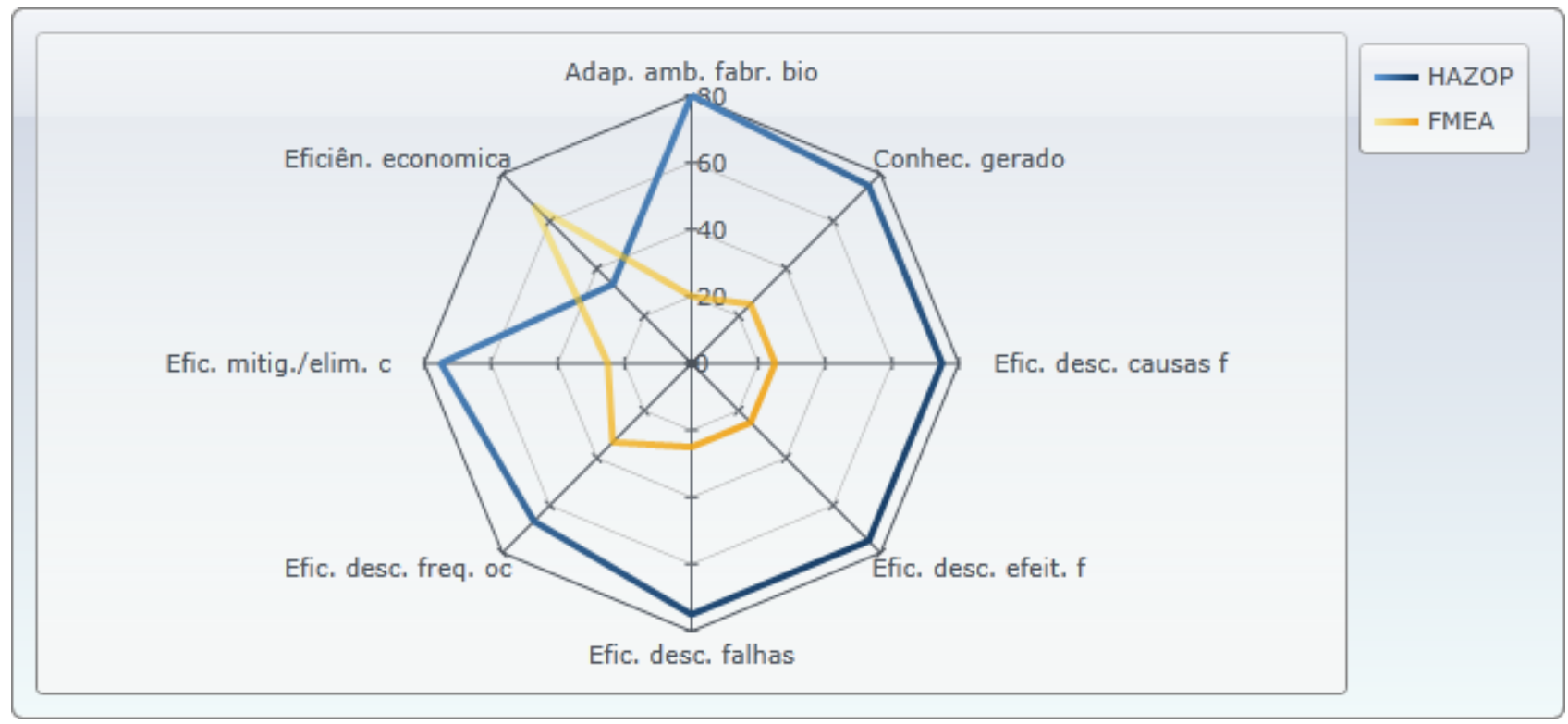

Fonte: Elaboração própria

Figura 7 - Resultado da comparação entre HAZOP e FMEA em gráficos de barras

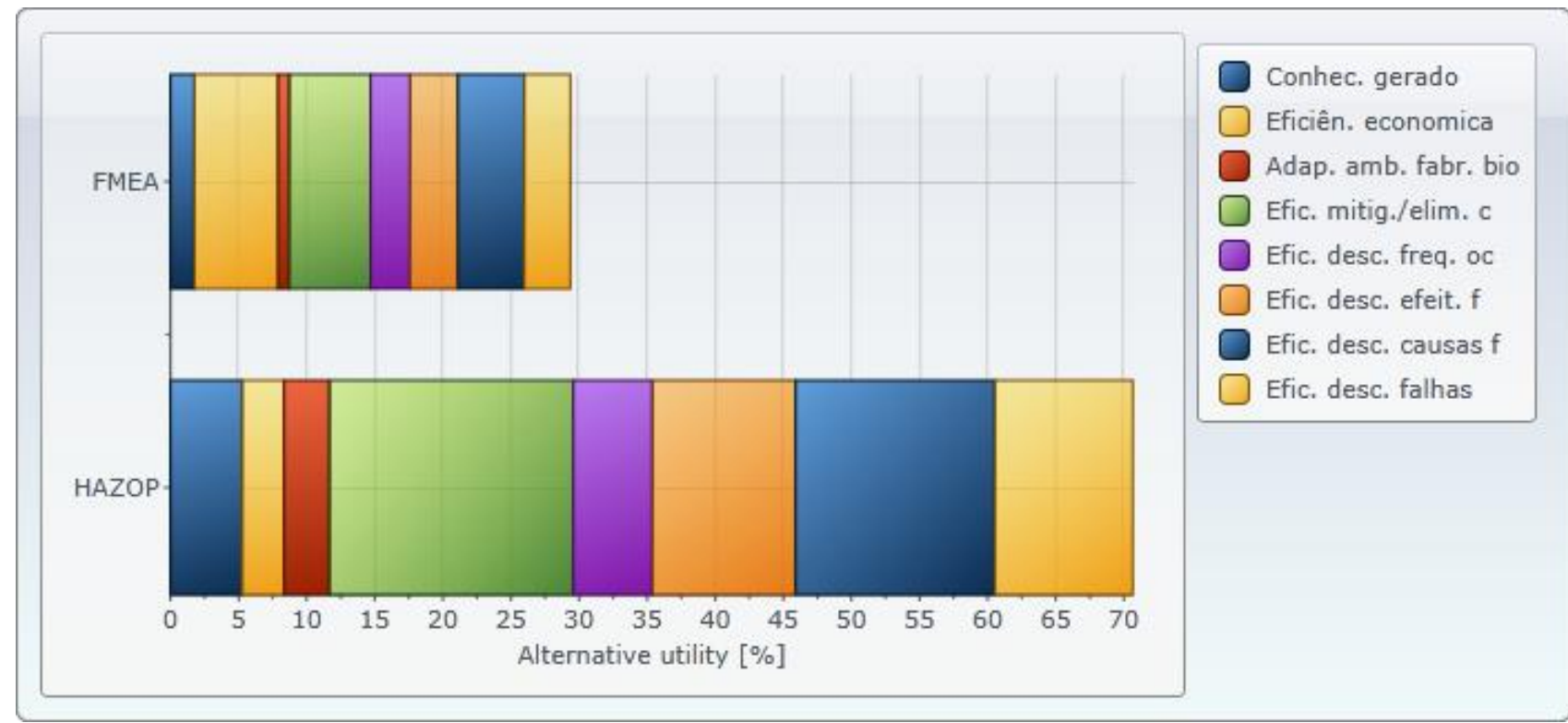

Fonte: elaboração própria

\section{Conclusões}

O desenvolvimento de medidas de prevenção de falhas em usinas sucroenergéticas é conduta de grande interesse das usinas produtoras de bioetanol, pois as falhas e desvios no sistema de fabricação afetam diretamente a produtividade da fábrica. Neste contexto, este artigo teve como objetivo analisar comparativamente FMEA x HAZOP aplicados ao ambiente de fabricação do bioetanol de cana-de-açúcar. 
A partir do grau de detalhamento dos fatores atuantes no sistema operacional que é demandado pela aplicação de ambos os métodos analisados, pode-se inferir que tanto o FMEA quanto o HAZOP requerem um alto nível de compreensão do sistema em que se está atuando. Como primeira consequência, exigem-se funcionários gabaritados com larga experiência na fabricação para poderem trabalhar com estes métodos. Como segunda consequência, ambos os métodos são dependentes da subjetividade da equipe de desenvolvimento, já que há apreciável nível de suposições relativamente aos efeitos e às possibilidades de correção/prevenção.

Para lidar com a complexidade do objetivo traçado, aplicou-se o método AHP, o qual é interessante quando os elementos constituintes do processo de tomada de decisão são difíceis de quantificar ou comparar, ou quando o relacionamento entre os elementos é dificultado por terminologias ou perspectivas muito distintas. A utilização do método AHP envolveu a sinopse matemática de várias arbitragens sobre o problema de decisão. A questão central do AHP esteve calcada não apenas na determinação do peso com os quais os fatores individuais do nível mais baixo da hierarquia influenciaram o fator máximo, o objetivo geral, mas também na avaliação confrontativa entre os dois métodos sob o ponto de vista de cada especialista e, sob o balizamento de cada critério de comparação criado.

Entre os oito critérios de comparação, os pesos dos quatro primeiros somados correspondem a $71 \%$ do total. Estes resultados demonstram certa lógica sob o panorama da prevenção de falhas na indústria, pois se relacionam à (na ordem): 1) eliminação das causas das falhas, dado que não se pode eliminar um problema sem aniquilar suas fontes geradoras; 2) descoberta da causa da falha, já que não é possível eliminar as causas sem antes identificá-las; 3) descoberta dos efeitos das falhas, dado que é por meio do reconhecimento dos efeitos que se pode chegar à dimensão da severidade do problema; 4) descoberta da falha, visto que é o reconhecimento da falha que inicia todo o transcurso rumo à sua prevenção.

Como resultado final, o método FMEA apresentou, sob a ótica da equipe estabelecida, desempenho superior ao HAZOP apenas sob a luz do critério "eficiência econômica de desenvolvimento". Em todos os demais critérios, o HAZOP foi considerado superior ao FMEA. Desta forma, pôde-se concluir que, no âmbito da fabricação do bioetanol, enquanto o FMEA exibiu desempenho relativo de $29 \%$ o HAZOP teve desempenho de $71 \%$. Ou seja, no tocante ao contexto estudado, o desempenho do método HAZOP foi considerado aproximadamente duas vezes e meia superior ao do método FMEA.

\section{Abstract}

The objective of this work is to develop a comparative study between the FMEA and HAZOP methods applied to bioethanol manufacturing environment. The work develops, in the form of categorical indicators congruent with the fundamental logic of so-called root cause 
analysis methods, eight criteria in order to balancing FMEA versus HAZOP. Then, weigh up quantitatively the developed criteria. Finally, the two methods are compared in the overview of each of the eight indicators developed. The job of weighting the criteria and subsequent confrontation between FMEA x HAZOP was conducted by the Analytic Hierarchy Process (AHP) method. The judgments required to the AHP method were performed by a team of experts from the São Paulo sugar energy industry. The consistency test showed that the values assigned to relative priorities can be judged consistent. As a result, HAZOP method was considered superior to about two and a half times over FMEA method within the context studied.

Key-words: FMEA method; HAZOP method; AHP method; bioethanol production.

\section{Referências}

AGUIAR, L. A. Metodologias de análise de riscos APP e HAZOP. Rio de Janeiro. Disponível em: <http://professor.ucg.br/SiteDocente/admin/arquivosUpload/13179/material/APP_e_HAZOP.pdf>. Acesso em: Jan. 2014.

BELLINI, V. Metodologia para análise dos modos de falha aplicada à segurança de condicionadores de ar. Florianópolis, 2008. 53p. Dissertação (Mestrado em Engenharia Mecânica). Universidade Federal de Santa Catarina.

BRITSH STANDARD INSTITUTION. BS IEC 61882:2001: hazard and operability studies (HAZOP Studies) application guide. UK, 2001.57 p. Disponível em:

<http://paulthorn.co.uk/healthandsafety/Risk\%20Management/HAZOP\%20BS\%2061882-2001.pdf>. Acesso em: 16 dez. 2013.

FERNANDES, J. M. R.; REBELATO, M. G. Proposta de um método para integração entre QFD e FMEA. Revista Gestão e Produção, v.13, n.2, p.245-259, 2006. cross ref

GANO, D. L. Apollo root cause analysis: a new way of thinking. Yakima, WA: Apollonian Publications, 2003.

GOULD, J. Review of hazard identification techniques. Health and Safety Laboratories. 2000. Disponível em: <http://www.hse.gov.uk/research/hsl_pdf/2005/hs10558.pdf>. Acesso em: jan. 2014.

NAVES, R. M. Análise hierárquica de sistema de bilhetagem eletrônica. Rio de Janeiro, 2008. 96p. Dissertação (Mestrado em Engenharia de Transportes). Universidade Federal do Rio de Janeiro, COPPE.

OLIVEIRA, A. A.; COSTA, J. A. F.; NETO, M. V. S. Aplicação do método de análise hierárquica na tomada de decisão para a adoção de computação em nuvem. In: SIMPOI, 2011. São Paulo: FGV-EAESP, 2011.

PQRI. Hazard \& Operability Analysis (HAZOP). Manufacturing Technology Committee - Risk Management Working Group - Risk Management Training Guides. Disponível em:

<http://www.oshrisk.org/assets/docs/Tools/3\%20Conduct\%20Risk\%20Assessments/HAZOP_Training_Guide.pdf>. Acesso em: jan. 2014.

PUENTE, J.; PINO, R.; PRIORE, P.; FOUENTE, D. L. A decision support system for applying failure mode and effects analysis. International Journal of Quality \& Reliability Management, v. 19, n. 2, p. 137-151, 2002.

REBELATO, M. G. ; MADALENO, L. L. ; RODRIGUES, A. M. Um estudo sobre a aplicabilidade do JUST-IN-TIME na fabricação do etanol. Revista Produção Online, v. 12, p. 703-728, 2012. cross ref

REBELATO, M. G. ; MADALENO, L. L. ; RODRIGUES, A. M. Ponderação do impacto ambiental dos resíduos e subprodutos da produção industrial sucroenergética. Revista Gestão Industrial, v. 9, p. 395-419, 2013. crossref

SAATY, T. L. Creative thinking, problem solving and decison making. Pittsburgh: RWS Publications, 2010.

SAATY, T. L. Decision making for leaders: the Analitic Hierachy Process for decisions in a complex world. Pittsburgh: RWS Publications, 2008.

SAATY, T. L. Método de Análise Hierárquica. São Paulo: Makron Books, 1991.

SHIMIZU, T. Decisão nas organizações. $3^{\mathrm{a}}$ Ed. São Paulo: Atlas, 2010. 
SMALL, D. Playing it safe: areas of focus for safety compliance. Ethanol Producer Magazine. June, 2008. Disponível em:<http://www.ethanolproducer.com/articles/4285/playing-it-safe-areas-of-focus-for-safety-compliance>. Acesso em: jan. 2014.

STUPIELLO, J. P. Extração de frações de destilação - Álcool hidratado. Apresentação realizada no seminário agroindustrial - STAB, Fenasucro-Agrocana 2012. Sertãozinho, agosto de 2012.

\section{Dados dos autores:}

Nome completo: Marcelo Giroto Rebelato

Filiação institucional: FCAV - UNESP - Jaboticabal

Departamento: Economia Rural

Função ou cargo ocupado: Professor

Endereço completo para correspondência (bairro, cidade, estado, país e CEP): Via de Acesso Prof.

Donato Castellane s/n - 14884-900 - Jaboticabal - SP

e-mail:mgiroto@fcav.unesp.br

Nome completo: Leonardo Lucas Madaleno

Filiação institucional: Centro Paula Souza - FATEC/Jaboticabal

Função ou cargo ocupado: Professor

Endereço completo para correspondência (bairro, cidade, estado, país e CEP): Via de Acesso Prof.

Donato Castellane s/n - 14884-900 - Jaboticabal - SP Telefones para contato: 1632026519

e-mail: leoagro@gmail.com

\section{Nome completo: Gustavo Borba Ferrari}

Filiação institucional: FCAV - UNESP - Jaboticabal

Departamento: Economia Rural

Endereço completo para correspondência (bairro, cidade, estado, país e CEP): Via de Acesso Prof.

Donato Castellane s/n - 14884-900 - Jaboticabal - SP

e-mail: borbagustavo@hotmail.com

Nome completo: Andréia Marize Rodrigues

Filiação institucional: FCAV - UNESP - Jaboticabal

Departamento: Economia Rural

Função ou cargo ocupado: Professora

Endereço completo para correspondência (bairro, cidade, estado, país e CEP): Via de Acesso Prof.

Donato Castellane s/n - 14884-900 - Jaboticabal - SP 
e-mail: andreiamarize@fcav.unesp.br

Submetido em: 30/01/2014

Aceito em: 18/12/2014 